\title{
A fire risk assessment model for residential high-rises with a single stairwell
}

Hansen, N. D.; Steffensen, F.B.; Valkvist, M.B.; Jomaas, Grunde; Van Coile, R.

Published in:

Fire Safety Journal

Link to article, DOI:

10.1016/j.firesaf.2017.11.006

Publication date:

2018

Document Version

Early version, also known as pre-print

Link back to DTU Orbit

Citation (APA):

Hansen, N. D., Steffensen, F. B., Valkvist, M. B., Jomaas, G., \& Van Coile, R. (2018). A fire risk assessment model for residential high-rises with a single stairwell. Fire Safety Journal, 95, 160-169.

https://doi.org/10.1016/j.firesaf.2017.11.006

\section{General rights}

Copyright and moral rights for the publications made accessible in the public portal are retained by the authors and/or other copyright owners and it is a condition of accessing publications that users recognise and abide by the legal requirements associated with these rights.

- Users may download and print one copy of any publication from the public portal for the purpose of private study or research.

- You may not further distribute the material or use it for any profit-making activity or commercial gain

- You may freely distribute the URL identifying the publication in the public portal 


\title{
A fire risk assessment model for residential high-rises with a single stairwell
}

\author{
Hansen, N.D., Steffensen, F.B., Valkvist, M., Jomaas, G., Van Coile, R.
}

\begin{abstract}
As few or none prescriptive guidelines for fire risk assessment of residential high-rise buildings exist, it has been unclear which fire safety design features constitute an acceptable (adequate) safety level. In order to fill this gap a simplified risk-based decision-support tool, the Fire Risk Model (FRM), was developed. The FRM evaluates both the risk level to the occupants and the property risk level as a function of the building characteristics, height and fire safety features for single stairwell residential high-rise buildings. The acceptability of a high-rise design is then defined through comparison with the risk level associated with a $22 \mathrm{~m}$ high prescriptive design. The FRM and its applicability are introduced by summarily revisiting the concept of equivalency and adequate safety. The underlying assumptions and the pitfalls of equivalency assessments are discussed, and the associated performance of the FRM evaluated. It was found that compartmentation and the door configurations in the egress path play an important role, along with sprinklers, in order for the design to successfully keep the stairwell free from smoke. Specifically, modern curtain wall facades were found to result in a reduced safety level compared to traditional facades with a spandrel. When opting for a modern curtain wall, additional safety features were found to be required in order to obtain an equivalent safety level.
\end{abstract}

\section{GENERAL INTRODUCTION}

According to the Oxford dictionary, fire safety engineering is concerned with the prevention of fire risk and the promotion of safety. To this end, fire safety engineers have a large array of fire safety measures at their disposal, including building layout, alarm systems, pressurized stairs, fire doors, evacuation lifts, passive fire protection boards and sprinkler systems, to name but a few. Arguably all of these safety measures reduce the fire risk, or at the very least can generally be considered not to worsen the safety level. If fire safety measures could be installed free of costs and there were no design constraints, it would be an easy conclusion to include all thinkable safety features in any possible design.

Fire safety measures however do come at a cost, both in monetary and sometimes architectural terms. Often a choice has to be made between different systems as the implementation of one system is incompatible with the implementation of another. A staircase, for example, cannot at the same time be both pressurized and open to the outside environment. Furthermore, there may be situations where even our best efforts and most advanced fire safety systems are insufficient to result in an 'adequate' level of safety and where the project can therefore not be realized with currently available fire safety technology. 
In traditional design approaches, adequate safety has been defined through the collective experience of the profession (Ditlevsen and Madsen, 2005), (Hopkin et al., 2017). More specifically, continued trial and error combined with public outcry at unacceptable failures have gradually resulted in current-day prescriptive design rules (Spinardi et al., 2017). It is however crucial to realize that the reliance on the 'collective experience of the profession' can only hold when there are ample example cases to learn from, guiding the prescriptive design rules towards an (optimum) acceptable safety level. In technical terms, this would be when there is sufficient sampling of the failure space. Consequently, the justification of adequate safety through experience does not hold by definition for exceptional structures such as airports, dams and skyscrapers, for very low probability events or for innovative building designs and materials (Croce et al., 2008). In those situations, adequate safety cannot be based on the presumed collective experience and must necessarily be demonstrated.

It is often argued that the accepted design solutions in current prescriptive rules incorporate an implicit evaluation of the safety level required by society (Fischer, 2014 and Lundin, 2005), and thus constitute a benchmark for 'adequate safety'. Then, the adequacy of an 'innovative' or 'nontraditional' design can be demonstrated by comparing its safety level with the safety level associated with the prescriptively accepted design solution (BSI, 2003). This is commonly known as demonstrating equivalency or equivalent safety, and in many countries this is a common procedure to justify deviations from prescriptive design guidance (He and Grubits, 2010; Fischer, 2014; Wu et al., 2014). As many assumptions underlying the safety evaluations for both the innovative and the traditional design solution can be the same, the effect of these assumptions are often considered to cancel out when comparing the obtained safety levels, allowing for an easier acceptance by the authorities and reducing the required complexity of the input data (BSI, 2003). For example, when considering the performance of different façade designs with respect to the annual probability of reaching dangerous radiation intensities at the opposite façade, the fire ignition frequency for the compartment can reasonably be considered the same in both design approaches, eliminating the need for a detailed evaluation of fire ignition mechanisms (Van Coile et al., 2016).

There are a number of essential caveats that must be kept in mind with respect to the demonstration of equivalence. The following pitfalls are based, amongst others, on the discussion in Fischer (2014).

1. Prescriptive fire safety codes do not necessarily correspond with optimum safety levels. While prescriptive requirements can be assumed to converge to the implicit societal expectations for fire safety given enough time and observed failures (i.e. after infinite learning opportunities), the tradition of modern fire safety regulations is relatively young and the number of observed failures is limited. This is especially the case with respect to low probability, high consequence events.

2. Safety levels incorporated in prescriptive guidance differ between building types. Consequently, there is room for influencing the comparison through the choice of prescriptive design solution used as a benchmark for the comparison. 
3. The application of prescriptive guidance to structures that are outside the scope of the guidance document cannot result in a benchmark for adequate safety. Consequently, the scope of the building must necessarily remain inside the (extended) scope of the prescriptive standard when demonstrating equivalency. Here, 'extended' refers to the introduction of a new lining or façade material, for example, or an increase in building height compared to the accepted design. Thus, it is in principle not possible to demonstrate adequate safety in an airport terminal by showing a safety level exceeding the safety level obtained when applying common building regulations for congregation areas.

4. Modelling assumptions and simplifications applied in the safety evaluation do not necessarily have the same effect on both the prescriptive design solution and the innovative design. This issue is especially troublesome, as it is both difficult to detect and contrary to intuition (i.e. based on intuition, application of the same 'conservative' modelling simplifications to both designs would generally be considered to be a reasonable procedure). The direction and size of this asymmetry effect is often difficult to predict and in specific cases it may be possible to influence the equivalency evaluation through the choice of modelling assumptions. Consider for example the equivalency assessment of an alternative design where an improved smoke control system is implemented to offset extended travel distances. The sprinkler system could be conservatively assumed not to suppress the fire in the evacuation assessment, but the exclusion of sprinkler protection may be especially onerous for the prescriptive design solution.

Nevertheless, comparative safety (equivalency) evaluations are extensively applied in fire safety engineering and can be a very valuable tool in well-defined circumstances. By illustrating the benefits that can be obtained through comparative safety evaluations and indicating how the comparative safety pitfalls listed above have been avoided, the Fire Risk Model (FRM) presented herein provides a tool for the comparative safety assessment of high-rise residential buildings with a single staircase. The tool was developed by Hansen (2012) in response to a pressing need to easily assess the safety requirements for high rise residential buildings in Denmark after the introduction of performance-based fire safety regulations (e.g. Energistyrelsen, 2010). The discussions below introduce the background of the model, its underlying assumptions, the range of applicability, and present application results.

\section{CASE DESCRIPTION}

In 2004, Denmark moved from prescriptive fire safety regulations to a performance-based framework. A guidance document was published in support of the performance-based design philosophy detailing examples of accepted design solutions (Energistyrelsen, 2012a). However, these solutions only cover buildings up to $22 \mathrm{~m}$ in height (of the top story floorplate). This limiting height is based on the length of the Danish rescue service's mechanical ladders - both for extinguishment and rescue purposes. Nevertheless, as other countries, Denmark has been experiencing a trend towards tall residential buildings, with more and more high-rise apartment buildings being planned and built (Kobenhavs Kommune, 2006). A draft document with prescriptive guidelines for tall buildings was published later in 2012 (Energistyrelsen, 2012b), but while a large body of experience exists for low rise residential buildings, the portfolio of high-rise 
residential buildings is much smaller, resulting in a risk that the prescriptive high-rise guidance does not fully correspond with societal expectations. Therefore, practical design assistance tools for evaluating the adequacy of the fire safety features in high-rise residential buildings would be of direct value to both the fire safety engineers and the authority having jurisdiction (AHJ).

Considering the above, an easy-to-use quantitative Fire Risk Model (FRM) was developed to support decision making of both fire safety professionals and authorities having jurisdiction (AHJ). The FRM intends to give a fast and robust order-of-magnitude assessment of the acceptability of proposed design solutions, while explicitly taking into account the many uncertainties associated with the relevant input parameters. As residential buildings in Denmark traditionally have only a single stairwell, the FRM has been developed specifically to assess the need for additional safety features when extending the height of single stairwell buildings. Furthermore, it is important to note that the FRM relates to the design of new residential, single stairwell buildings. This has important implications as, for example, protrusions in fire safety walls are required to be properly sealed with fire stopping (Energistyrelsen, 2010), (Sikkerhedsstyrelsen, 2001).

\section{DESCRIPTION OF THE FIRE RISK MODEL}

The Fire Risk Model (FRM) is developed as a tool for evaluating comparative safety. To this end, the accepted design solution for a $22 \mathrm{~m}$ tall residential building in (Energistyrelsen, 2012a) is considered as a benchmark defining adequate safety. Since considerable experience exists with respect to low- and medium-rise residential buildings, this design solution can be assumed to correspond closely with an empirical observation of societal fire safety preferences for multidwelling residential buildings. The FRM is developed in order to ensure adequate safety when increasing the residential building height. Therefore, special emphasis is put on the heightdependency of different aspects.

Note that the accepted design solution is considered to indicate an acceptable (adequate) safety level for multi-dwelling residential buildings only. The assumption is made that the adequacy of the safety level can be considered independent of building height. This assumption is expected to be acceptable within bounds (for example up to a building height of $150 \mathrm{~m}$ and a total occupancy of no more than 500 people). As the residential building becomes taller and houses more residents, it increasingly needs to be designed as an exceptional (unique) structure considering the limited current-day experience with this type of structures. Note that consequently extrapolation to other usage categories (office, nightlife), or exceptional buildings (airport terminal) is not considered acceptable.

The following introduces the considered fire risk objectives and applied risk indicators (Section 3.1). Further details on the modelling of the fire risk indicators are given in Sections 3.2 and 3.3. The different building characteristics and fire safety measures included in the FRM are presented in Section 3.4 together with a conceptual discussion on the influence of these parameters on the fire risk evaluation. Full details of the different models can be found in (Hansen, 2012).

\subsection{Fire safety objectives and risk indicators}


Fire risk equivalency is considered to constitute equivalency with respect to each of the different fire safety performance objectives derived from the Danish building regulations (Energistyrelsen, 2010): occupant safety, property protection, business continuity and environmental protection, although the current regulations focus on occupant safety. For residential buildings, occupant safety and property protection are considered determinative for the design, while the business continuity and environmental protection objectives are assumed to be of lesser importance for this type of building (specifically, the environmental and business continuity risk levels are considered negligible). Therefore, the business continuity and environmental protection objectives are not explicitly considered in the FRM.

The occupant safety and property protection fire safety objectives correspond respectively with an occupant risk level and a property risk level. As is common in engineering, the risk associated with an adverse event is defined through Eq. (1), with $P$ being the probability of the adverse event and $C$ being the expected value of the associated consequences (Hadjisophocleous and Benichou, 1999; Meacham, 2004). For an introduction to the historical development of the concept of 'risk', see (Doron, 2016). The use of expected consequences in this risk formulation implies that all possible consequences of the adverse event are weighted according to their probability. In order for this weighing to be reasonable, none of the possible consequences is allowed to be fundamentally unacceptable if it would materialize.

$$
R=P \cdot C
$$

Both for the occupant risk and the property risk, the occurrence of the adverse event is defined through a limit state whose exceedance is considered to constitute a failure with respect to the performance objective. With respect to occupant safety, the limit state is defined as 'smoke entering the stairwell during the evacuation'. This relates directly to the commonly encountered directive to maintain tenable egress routes in case of fire. An egress route exposed to (critical amounts of) smoke is considered untenable.

The consequence of the exceedance of the occupant safety limit state is defined by the expected number of occupants still present in the building when smoke enters the stairwell as the continued evacuation of these occupants can be hindered. Consequently, the occupant risk level $R_{O}$ is defined by (2), where $p_{S}$ is the annual probability of fire-induced smoke entering the staircase, and $N_{O}$ the number of occupants still present in the building when the adverse event occurs.

$$
R_{O}=p_{S} \cdot N_{O}
$$

The definition for the occupant risk level partially neglects the risk that occupants are unable to evacuate in case of a fire in their own apartment (for example because they are intoxicated by the smoke while sleeping). Although important from an absolute safety perspective, this aspect of risk to life is assumed not to be influenced by the height of the building and is on the contrary considered comparable to the corresponding risk in low-rise residential buildings. Consequently, this specific aspect of risk to life does not necessarily need to be explicitly considered when evaluating the need for increasing safety features with building height. More extensively, the total evacuation time of the building is determined by the vertical travel distance and as such the effect of extended horizontal travel distances is not taken into account. Note that it is theoretically 
possible to compensate an increased height-dependent risk level by reducing the heightindependent risk. This kind of reasoning is however blind to aspects of societal risk aversion (see e.g. Vrijling et al., 1995), and therefore the FRM has been explicitly developed to compare the height-dependent risk associated with multi-dwelling residential buildings.

The property risk level is related to the spread of fire. This relates closely to the common fire safety directives to ensure compartmentation and maintain load bearing capacity. If the fire is confined to the object of origin, damages will be limited and for these 'small fires' there arguably is very limited height-dependence of the risk. For larger, 'severe' fires however, the fire brigade accessibility, amongst others, is important and thus the property risk level equivalency assessment is considered to relate to severe fires only. Specifically, for the property risk level the adverse event is defined by the occurrence of a severe fire, with a severe fire defined as a fire sufficiently intense to activate a sprinkler system. Fires which are not capable of activating the sprinkler system (either because of their inherent burning characteristics or because of swift suppression by the occupants) are considered not to contribute to the height-dependent property risk.

The consequences of a severe fire are evaluated as monetary damages, $D_{f i}$, and are considered to be proportional to the extent of fire spread (i.e. the area affected by the fire, $A_{f i}$ ) and the property value per $\mathrm{m}^{2}, C_{0}$. The proportionality constant relating $A_{f i} C_{0}$ to $D_{f i}$ is not important for the comparative evaluation. Whenever absolute values are calculated as example output, a proportionality constant of 1 will be used. Further important aspects of the property risk sub-model are discussed in Section 3.3.

In conclusion, the property risk level $R_{P}$ is defined by (3), with $p_{f i}$ is the annual probability of a severe fire, and $D_{f i}$ the associated (expected) monetary damages.

$$
R_{P}=p_{f i} \cdot D_{f i}
$$

Both the occupancy risk level and the property risk level relate to an idealized definition of the adverse event and associated consequences. Consequently, the absolute values of the risk assessment have no direct meaning and large differences can be observed with absolute risk assessments in other methods (Johansson, 2010). More precisely, some of the modelling assumptions have a large influence on the absolute risk assessment, but only a very limited or even no effect on the relative safety evaluation. While the input data to the FRM is based on statistical observations and evidence-based engineering judgement, it is not the intention to make a prediction of expected number of casualties and actual fire losses. The sole goal of the FRM is to make an informed judgement on equivalency for high-rise residential buildings falling outside the scope of the accepted design solutions for low-rise buildings as presented in (Energistyrelsen, 2012a).

The actual equivalency assessment is based on the relative safety level for the occupants (RSO) and property (RSP), as defined by (4) and (5), where $R_{O \text {,ref }}$ and $R_{P, \text { ref }}$ are the occupant and property risk levels associated with the $22 \mathrm{~m}$ high reference design deemed acceptable by the prescriptive guidance. When the fire safety features reduce the occupant risk level $R_{O}$ below the reference risk

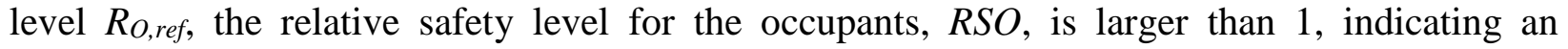


improvement in occupant safety level and (principal) acceptability of the design. The same reasoning applies to the equivalency evaluation for the property risk through $R S P$.

$$
\begin{aligned}
& R S O=\frac{R_{O, r e f}}{R_{O}} \\
& R S P=\frac{R_{P, r e f}}{R_{P}}
\end{aligned}
$$

\subsection{Model for the occupant risk level}

Considering the adverse event definition for the occupant risk evaluation as smoke entering the staircase, the occurrence of this adverse event can be limited for example by introducing a lobby to separate the staircase from the apartments (i.e. through stairwell design), by increasing the probability of containing the fire to the room of origin (i.e. by installing sprinklers), and by introducing (or improving existing) fire doors to increase the time between fire occurrence and (considerable) smoke entering the staircase.

The occupant consequence level (i.e. the number of occupants still in the building) will on the one hand depend on the speed of warning and the time required for evacuation once warned, and on the other hand on the time-frame during which the staircase can be kept free of smoke. Contrary to the defend-in-place strategy, which is often recommended for tall buildings, a full fire-brigade initiated evacuation will be considered as a default when the fire is large, based on the assessments by the New Zealand Department of Building and Housing (Gardiner, 2005a, 2005b). For small fires (i.e. fires which are insufficiently powerful to result in sprinkler activation), there is no risk of smoke entering the staircase and the decision by the fire and rescue service to opt for a total evacuation has no effect on the calculated risk level. Note that the above thus assumes that the fire and rescue service always opts for a total evacuation, except when it is certain that the fire is small.

\subsection{Model for the property risk level}

In accordance with Danish regulations for new buildings (Energistyrelsen, 2010), the FRM considers all protrusions to be sealed with rated fire stoppings. It is therefore, conservatively, assumed that these internal fire stoppings are installed to standard. Thus, the dominant mode of vertical fire spread between floors is external contrary to observations in historical high-rise fires (Bittern et al., 2011).

It has been observed that multi-story fires can lead to partial or complete building collapse (e.g. Ikeda and Sekizawa, 2005; Flint et al., 2007; Lange et al., 2012) resulting in unpredictable direct and indirect consequences. Therefore, special emphasis is put on containing the fire on the floor of origin. Fire spread beyond the story of origin is considered as a complete failure of the property protection objective, (numerically) resulting in a full property loss for all higher floors. Note that the occupant risk model relates to smoke entering the single staircase and that a total (simultaneous) evacuation is assumed. Fire spread beyond the story of origin thus has no direct effect on the modelled occupant risk level. 


\subsection{Fire safety measures}

The occupant and property risk levels are determined through the interaction of different fire safety features, i.e. the building layout, passive fire protection systems, and active fire protection systems. Each of these features consists of a number of components, whose interaction is modelled through sub-models (Hansen, 2012).

The fire safety and building characteristics considered in the FRM are introduced below together with a concise description of the associated models and their influence on the occupant and property risk level through the FRM. A very extensive description of the sub-models is given in (Hansen, 2012). It must be emphasized that the sub-models and their interaction can readily be modified in the FRM to take into account new information or improved modelling assumptions, thanks to the FRM's modular design. For example, ongoing research projects are directed at extending the FRM's capabilities to multiple stairwell designs.

\subsubsection{Building characteristics}

The building layout characteristics are listed in Table 1 together with their influence in the FRM risk level evaluations. For high-rise buildings, and even more so for ones with a single stairwell, the stairwell design is of utmost importance and therefore, the stairwell design options are introduced separately in Section 3.4.2.

\section{Table 1: Building layout characteristics}

\begin{tabular}{ll}
\hline Parameter & Effect on FRM \\
\hline Building height [m] & $\begin{array}{l}\text { The building height is measured from ground level up to the floorplate of the } \\
\text { highest story. The height is determinative for the wind effect in case of an airlock } \\
\text { stairwell, and for the probability of effectiveness of the pressurization system in } \\
\text { case of a pressurized stairwell. Other effects are incorporated through the number } \\
\text { of stories. }\end{array}$ \\
$\begin{array}{l}\text { The number of stories defines the number of occupants. The number of occupants } \\
\text { determines the travel time when evacuating by the stairs, through the regression } \\
\text { proposed by Proulx (2008). The number of stories is also determinative for the } \\
\text { expected number of fire ignitions per year, the warning time in the absence of a } \\
\text { dedicated warning system, the setup time for the fire and rescue service, and the } \\
\text { size of the property losses in case of a total failure of the property protection } \\
\text { scheme* }\end{array}$ \\
$\begin{array}{l}\text { The area per story influences the expected number of fire ignitions per year, and } \\
\text { the size of the property losses (as a function of the fire spread extent). The } \\
\text { influence of the floor area on the total evacuation time is neglected relative to the } \\
\text { influence of the building height. }\end{array}$ \\
$\begin{array}{l}\text { Octerminative for the total number of occupants in the building. } \\
\text { [persons] }\end{array}$ \\
$\begin{array}{l}\text { Apartments per story [-] } \\
\text { Façade access (for assisted } \\
\text { evacuation) }\end{array}$ & $\begin{array}{l}\text { Determines the total number of occupants in the building, and the property loss as } \\
\text { long as the fire remains contained in the compartment (i.e. apartment) of origin. } \\
\text { Influences the number of persons that can be evacuated by the fire and rescue } \\
\text { service. Conservatively, it is assumed that façade access is not feasible for } \\
\text { modern curtain wall façade systems. }\end{array}$ \\
\hline
\end{tabular}




\begin{tabular}{ll}
\hline Spandrel height [m] & $\begin{array}{l}\text { Limits the probability of external fire spread between stories for traditional } \\
\text { façade systems by limiting the incident radiation to the next floor. The incident } \\
\text { radiation decreases with increasing spandrel height through the relationship } \\
\text { proposed in (Empis, 2010). }\end{array}$ \\
Façade system & $\begin{array}{l}\text { Influences the probability of fire spread beyond the story of origin. Traditional } \\
\text { façade systems limit the probability of external fire spread due to the spandrel } \\
\text { height and by giving the fire and rescue service additional time for external } \\
\text { intervention. Modern curtain wall facades lack these safety features. Intricate } \\
\text { aspects related to external fire spread in the façade due to material choice and } \\
\text { design failures have not been included. Amongst others, this implies that non- } \\
\text { combustible façade is assumed. }\end{array}$ \\
Glass & $\begin{array}{l}\text { For traditional façade systems, the window type (single, double, triple) influences } \\
\text { the available time for fire and rescue service to prevent external fire spread. As a } \\
\text { default, the windows are assumed to be closed. }\end{array}$ \\
Stair width [m] & $\begin{array}{l}\text { The stair width influences the distribution for the total evacuation time, with a } \\
\text { wider stair having a larger capacity for evacuation. }\end{array}$ \\
The apartment value per m² directly influences the property risk evaluation as the \\
property losses are considered proportional to the apartment value and the extent \\
[EUR $/ \mathbf{m}^{2}$ ]
\end{tabular}

* i.e. when the fire spreads beyond the floor of origin, or when the fire spreads beyond the compartment of origin and the equivalent fire duration exceeds the fire resistance of the structure.

The building height and number of stories are related through the story height. Herein, the story height is kept constant at $3.14 \mathrm{~m}$ (same value as in the $22 \mathrm{~m}$ high accepted design solution).

\subsubsection{Stairwell design options}

As there is only a single stairwell, the stairwell characteristics are of particular importance for the safe evacuation of the occupants. The stair width affects the building total evacuation time (as listed in Table 1 above). More important, the type of stairwell influences the smoke spread, as different stairwell designs can have a different number of doors and different barriers against smoke spread. Four different types of stairwell design are considered in the FRM, as visualized in Figure 1. The concepts of the different stairwell types are discussed in Table 2. The choice of stairwell has no influence on the property risk level as the stairwell design is considered not to influence the extent of fire spread, as there is no flammable content in the stairwells and the seals are working properly.

Specifically for the pressurized stairwell design, stairwell pressurization is considered noteffective when the stairwell door is open, based on (Klote, 2004). The negative effect of open doors has recently been observed in experiments by Acikyol et al. (2017). Furthermore, when the pressurization system correctly activates, its effectiveness probability is tentatively modelled by Eq. (6) (Hansen, 2012), indicating that for a $100 \mathrm{~m}$ tall building the success rate of the pressurization system is only approximately $20 \%$. This low success probability relates to the observation by Bittern et al. (2011) that stairwell pressurization failed to operate in 9 out of 10 the investigated cases. Less onerous, but still considerable failure probabilities have been reported in (Cowlard et al., 2013). Furthermore, Eq. (6) assumes a height-dependency of the pressurization system's effectiveness. This height-dependency takes into account for example the increased delays in the pressurization control system for tall buildings, as reported in (Bellido et al., 2009), and the increased probability that the door to the staircase will be open on multiple floors. 


$$
P_{\text {success, press }}=1-0.2 \ln (H / 2)
$$

The barrier to smoke spread constituted by a closed fire door is in the current version of the FRM associated with the fire resistance rating of the door and only marginal or no smoke spread is assumed for the duration of the fire resistance rating. Thus, an EI30 door is assumed to delay the exceedance of the smoke spread limit state by 30 minutes. However, proper functioning of the fire door requires the door to be closed, and thus the probability of the door being blocked or left open is considered as in (BSI, 2003). Thanks to the modularity of the FRM, the model for the fire door smoke barrier can readily be improved if more precise assessments are available. For a first level comparative study, the simplified assumption above is considered reasonable.

1)

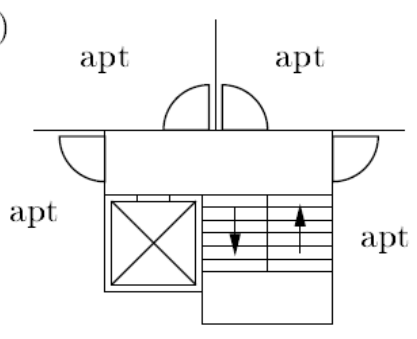

3)

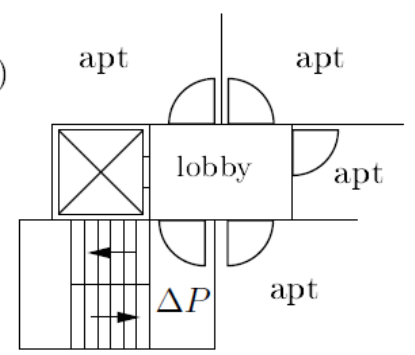

2)
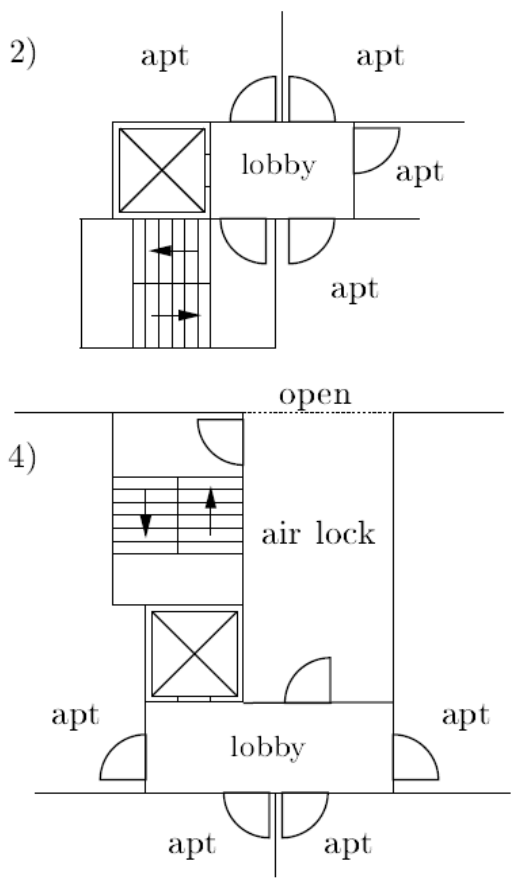

Figure 1: Stairwell types for a floor with four apartments: 1) Direct access to apartments ('direct access'); 2) Central lobby accessing both apartments and stair ('with lobby'); 3) Pressurized stair with central lobby ('pressurized'); 4) Central lobby and air lock space that is open to the outside ('air lock') before entering the stairwell.

Table 2: Stairwell types and characteristics

\begin{tabular}{ll}
\hline Stairwell type & Barriers against smoke spread \\
\hline Direct access & $\begin{array}{l}\text { The fire rating of the apartment door (compartment of fire origin - when door is } \\
\text { closed), and sprinkler system (when available and effective) as effective sprinkler } \\
\text { suppression contains the fire to the compartment of origin. }\end{array}$ \\
With lobby & $\begin{array}{l}\text { Barriers of direct access stairwell + additional fire rated door linking lobby to } \\
\text { stairwell. }\end{array}$ \\
Bressurized & $\begin{array}{l}\text { Barriers of lobby stairwell + additional barrier of successful pressurization. Failure } \\
\text { of the pressurization system is assumed to result either from a failure to activate or } \\
\text { a failure to perform effectively. Activation failure is considered to result from a } \\
\text { detection failure. The effectiveness of the system is considered a function of the }\end{array}$ \\
\hline
\end{tabular}


building height as specified by Eq. (6). However, when the door to the staircase is blocked open, the pressurization system is considered not to be effective, based on (Klote, 2004).

Air lock

The air lock is open to the outside and thus large smoke spread to the stairwell is considered to be possible only in conjunction with negative wind effects. The probability of negative wind effects is assumed proportional to the wind velocity and evaluated in function of the building height. Given the occurrence of negative wind effect, the air lock system still has the same barriers as the lobby stairwell + an additional barrier constituted by the (fire rated) door giving access to the airlock.

\subsubsection{Passive fire safety measures}

Different passive fire safety measures are included in the FRM. These are introduced in Table 3 together with a description of their effect on the risk level evaluations $R_{O}$ and $R_{P}$. The fire spread beyond the compartment of origin is modelled based on statistical data (Hasofer et al., 2007), independent of the structural fire resistance rating. The underlying dataset relates to unsprinklered UK apartment buildings in the time-period 1983-1991. More recent datasets can be taken into account when available. The effect of sprinklers on fire spread is taken into account considering the fire confinement success rates listed by Hall (2010).

Table 3 specifies that the structural fire resistance rating is compared with a stochastic fire severity when fire spreads beyond the compartment of origin, defining total building loss when the fire severity exceeds the fire resistance. The stochastic fire severity is defined by the EN 1991-1-2 (CEN, 2002) equivalence formula (Annex $\mathrm{F}$ of the standard), relating a given fire load density to an equivalent ISO834 standard fire duration. The fire load density in an apartment is modelled through a normal distribution, with mean of $800 \mathrm{MJ} / \mathrm{m}^{2}$ and standard deviation of $220 \mathrm{MJ} / \mathrm{m}^{2}$, based on (Axelsson et al., 2012). Together with a ventilation parameter $w_{f}$ of 1.5 and enclosure parameter $k_{b}$ of $0.07 \mathrm{~min} \cdot \mathrm{m}^{2} / \mathrm{MJ}$ (see EN 1991-1-2 for definitions), the specified fire load probability density function thus corresponds with a probability density function for the equivalent fire severity. It is acknowledged that the above model for defining total building loss is very much simplified, but it is intended to give a first evaluation of (the benefit of increasing) structural fire resistance. The FRM can be adapted with more advanced assessments when available.

Table 3: Passive fire safety measures and conceptual description of effect on risk indicators $\boldsymbol{R}_{O}$ and $\boldsymbol{R}_{P}$

\begin{tabular}{ll}
\hline Apartment door & $\begin{array}{l}\text { When fire-rated, smoke spread to the lobby (or direct access stairwell) is } \\
\text { inhibited for the duration of the fire-rating. The door fails to function properly } \\
\text { when left or blocked open by the occupants. The provision of self-closing } \\
\text { devices reduces this probability. }\end{array}$ \\
$\begin{array}{l}\text { Stairwell door } \\
\text { Airlock door }\end{array}$ & $\begin{array}{l}\text { Same functionality as the apartment door. } \\
\text { Structural fire } \\
\text { resistance rating [min] }]\end{array}$ \\
$\begin{array}{l}\text { The structural fire resistance rating is determinative for the time available to the } \\
\text { fire and rescue service to assist in the evacuation of the occupants. Furthermore, } \\
\text { when fire spreads beyond the compartment of origin, the structural fire resistance } \\
\text { rating is compared to the stochastic fire severity (evaluated in accordance with } \\
\text { EN 1991-1-2 (CEN, 2002)). When the fire severity exceeds the fire resistance, } \\
\text { property losses associated with the entire building are assumed. }\end{array}$ \\
\hline
\end{tabular}




\subsubsection{Active fire safety measures}

Active fire safety measures included in the FRM are listed in Table 4, together with a description of their importance in the model.

Table 4: Passive fire safety measures and conceptual description of effect on risk indicators $\boldsymbol{R}_{O}$ and $\boldsymbol{R}_{P}$

\begin{tabular}{ll}
\hline Smoke alarm & $\begin{array}{l}\text { The provision of a smoke alarm in each apartment influences both the occupant } \\
\text { risk and the property risk by influencing the arrival time of the fire and rescue } \\
\text { service through an increased probability of an occupant call to the fire and rescue } \\
\text { service (especially at night). }\end{array}$ \\
Availability of a sprinkler system increases the probability that the fire is \\
confined to the room of origin. This limits the risk of smoke spread to the stair \\
and the extent of the area affected by fire for the evaluation of property losses. \\
Also, sprinklers are considered to dilute the toxic smoke, resulting in a reduction \\
of the consequences when smoke does enter the stairwell. Furthermore, due to \\
system interconnectivity sprinkler activation results in a notification of the fire \\
and rescue service (with high reliability), increasing the probability of an early \\
arrival.
\end{tabular}

\subsection{Calculation procedure}

The occupant and property risk level are evaluated in the FRM through fault-tree analysis (BSI, 2003, explicitly specifying all possible combinations of uncertain events (sprinkler activation, open door...) as a distinct possible scenario. Note that the sum of the scenario probabilities is necessarily equal to unity, as all possibilities are considered. The scenario-specific occupant and property risk levels are subsequently evaluated in accordance with Eq. (1) and summed together to specify the overall occupant risk level $R_{O}$ and property risk level $R_{P}$ for a given design. The ratio to the reference risk levels results in the relative safety levels RSO and RSP as specified in Eq. (4) and (5), and immediately gives an indication of the acceptability of the proposed design. As all equations are analytical, the evaluation of the FRM is quasi-instantaneous, allowing for immediate first-level feedback on different design options.

\section{RESULTS FROM THE FIRE RISK MODEL}

\subsection{Reference building and example relative safety evaluations}


The reference building for the equivalency assessment is a $22 \mathrm{~m}$ high residential building designed in accordance with the prescriptive guidance of (Energistyrelsen, 2012a). The associated building and fire safety characteristics are listed in Table 5.

Table 5: Building characteristics. An equality sign indicates that the parameter is maintained the same as in the reference building for all evaluations in this paper.

\begin{tabular}{|c|c|c|}
\hline Parameter & Reference building & $\begin{array}{l}\text { Assessed buildings } \\
\text { Section } 4.2\end{array}$ \\
\hline Building height [m] & 22 & Variable, function of number of stories \\
\hline Number of stories [-] & 8 & Variable \\
\hline Area per story $\left[\mathrm{m}^{2}\right]$ & 600 & $=$ \\
\hline Occupants per apartment [persons] & 2.5 & $=$ \\
\hline Apartments per story [-] & 4 & $=$ \\
\hline Stair type $[-]$ & Direct access & Variable \\
\hline Stair width [m] & 1 & 1 \\
\hline Apartment door & EI30 & EI30 \\
\hline Stairwell door & None & EI30 \\
\hline Airlock door & None & EI30 \\
\hline Smoke alarm & Domestic & Domestic \\
\hline Sprinkler system & None & Yes \\
\hline $\begin{array}{l}\text { Automatic smoke detection system } \\
\text { (ASDS) }\end{array}$ & None & $=$ \\
\hline Fire-fighting elevator & None & $=$ \\
\hline Warning system & None & Variable \\
\hline Structural fire resistance rating [min] & 120 & Variable \\
\hline Façade access (for assisted evacuation) & Yes & No \\
\hline Spandrel height [m] & 1.2 & $\begin{array}{c}= \\
\text { Not applicable for curtain-wall façade }\end{array}$ \\
\hline Façade system & Traditional & Variable \\
\hline Glass & Double-pane & $=$ \\
\hline Apartment value $C_{0}\left[\mathrm{EUR} / \mathrm{m}^{2}\right]$ & 470 & $=$ \\
\hline
\end{tabular}

The reference occupant and property risk levels, $R_{0, \text { ref }}$ and $R_{P, \text { ref, }}$, are evaluated considering the reference building characteristics and the fire safety features specified Table 5 . The reference building has a traditional façade with external openings within reach of the fire and rescue service, allowing for assisted external evacuation. Many modern buildings however have a curtain-wall façade system which does not allow for external evacuation. Furthermore, for high-rise buildings the higher locations of external openings are necessarily beyond the reach of the fire and rescue service appliances. The unavailability of an additional external evacuation path however strongly influences the occupant risk level. Figure 2 compares the relative safety level for the occupants (RSO), as defined by Eq. (4), as a function of building height (number of stories), when considering a traditional façade system with façade access, to the RSO obtained considering a modern curtainwall (without the possibility of assisted external evacuation). The curve for the traditional façade design is dotted for heights above $22 \mathrm{~m}$ to indicate that these results are for illustrative purposes only as current fire and rescue service appliances in Denmark only allow for an assisted rescue up to $22 \mathrm{~m}$. Note that the RSO for the traditional façade design is equal to 1 at $22 \mathrm{~m}$, in accordance with the RSO definition of Eq. (4) since this point corresponds exactly with the reference building of Table 5. By adding sprinklers to the curtain-wall design, the RSO performance is improved and $\mathrm{RSO} \geq 1$ is obtained up to 11 stories (approximately $31 \mathrm{~m}$ ). More extensive parameter studies and discussions are presented in Section 4.2. 


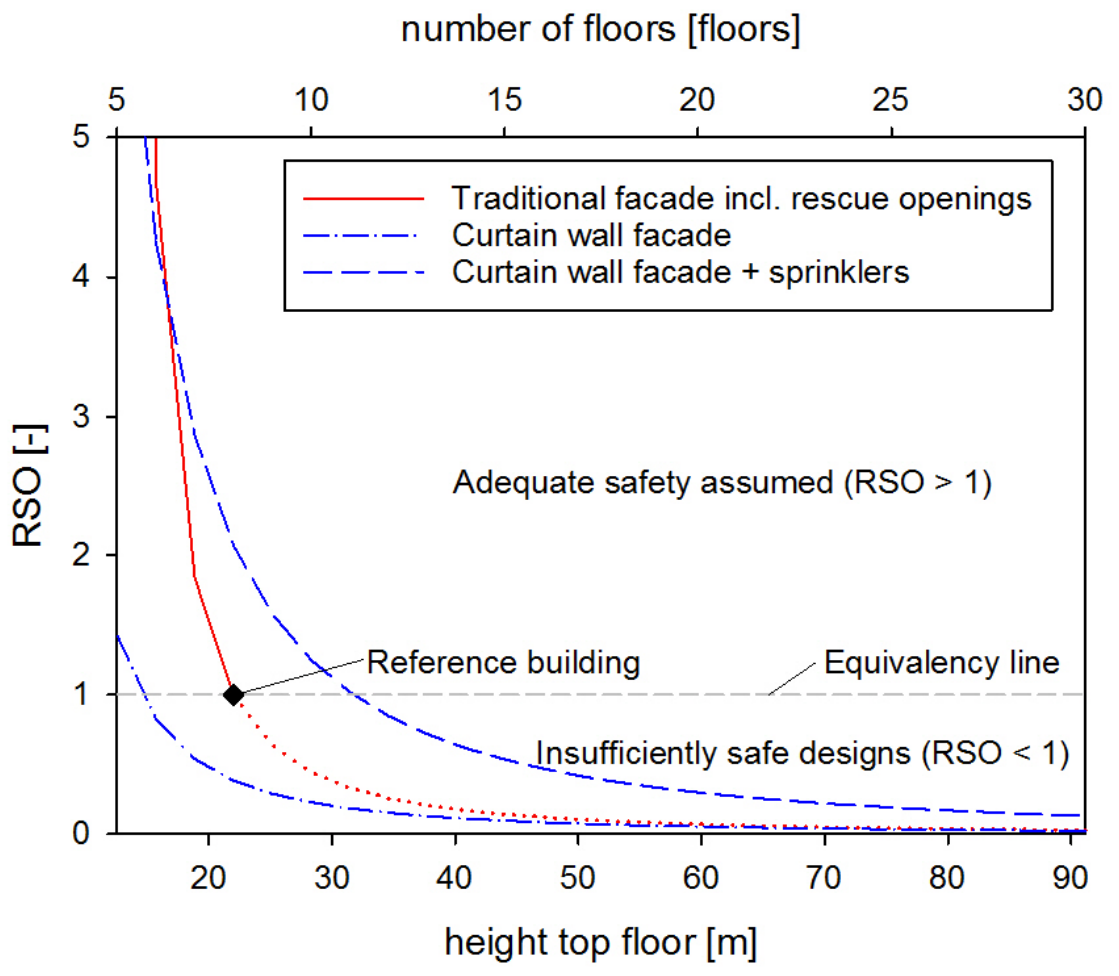

Figure 2: Relative Safety level Occupants (RSO) considering a traditional façade design with rescue openings (considered active above $22 \mathrm{~m}$ for illustrative purposes), a modern curtain-wall design (i.e. no rescue openings), and a curtain-wall combined with sprinklers, all other parameters as in the reference building as presented in Table 5, no warning system.

In a 'traditional' interpretation, the above evaluation of the FRM indicates equivalency with respect to occupant safety, and thus an (assumed) adequate occupant safety level, up to $31 \mathrm{~m}$ when opting for a curtain wall (without rescue openings) and compensating for the reduction of occupant safety compared to a traditional accessible façade by introducing sprinkler protection.

Modelling assumptions may result in asymmetric effects for the accepted reference design and the compared 'innovative' or 'deviating' design, as indicated in Point 4 of the equivalency pitfalls in the Introduction (Section 1). This is one reason to introduce a safety factor in the equivalency assessment. Another possible reason is the issue of risk aversion (Vrijling et al., 1995). The latter results in a reduced acceptance of risk level (probability x consequences) for high consequences (i.e. multiple fatalities). A detailed discussion of risk aversion is beyond the scope of this paper. Nathwani et al. (1997) however emphasize that a societal decision maker has an obligation to be risk neutral, as the societal decision maker must allocate funds to control various risks in a way that societal welfare is maximized (i.e. in a way that the most lives are saved). Societal outcry after a multi-fatality event can possibly partly be ascribed to availability biases in the wake of a disaster, see e.g. (Kahneman, 2011) for a general discussion of the concept. Also, the occurrence of a disaster can be considered to implicitly update the prior assessment of its likelihood (Bayesian updating), thus mathematically resulting in a higher evaluation of the risk level. When the risk level is assessed to be higher than originally thought, the accepted design solution needs to be updated as it is no longer considered to correspond with societal expectations for adequate safety. This updating of code requirements is regularly observed after disasters. In Denmark for example, 
the 1973 fire in Copenhagen's Hotel Hafnia and a fire 2 years later in a multi-story residential property resulted in updating the 1972 building regulations (Erhvervs- og Byggestyrelsen, 1972) to the 1977 edition (Erhvervs- og Byggestyrelsen, 1977).

Summarizing the above, the concept of risk aversion should be treated with special care when deciding on a safety factor. However, from the authors' perspective, at least the asymmetry of modelling effects warrants the introduction of a safety factor. This safety factor is necessarily subjective, as the direction and size of the asymmetry effect cannot readily be predicted. When an assessment tool (like the FRM) would be widely used, this safety factor can be assessed through an evaluation of multiple case-studies in a code-making committee.

In the absence of this type of information, the safety factor required in a specific case must be based on engineering judgement and an open discussion with stakeholders and the AHJ. More specifically, the obtained RSO (and RSP) should be presented to the stakeholders and AHJ, and when the relative safety level is much higher than unity (e.g. factor 2 or 3) the acceptability of the design will generally be clear. When the relative safety level is on the other hand close to unity, additional safety features may be requested by the stakeholders or AHJ to overcome their unease with respect to the proposed design. De facto this corresponds with the application of a safety factor or disproportion factor. From such a perspective, the FRM is a support tool for rational decision-making on fire safety features and is not a decision tool on itself. Still, the application of a risk-assessment tool can never result in a reduction of the designer's duty of care.

For the remainder of this paper, no safety factor is considered when evaluating equivalence (i.e. the safety factor is considered equal to unity).

\subsection{Parameter studies}

The relative safety will be evaluated further for different 'Assessed buildings'. The features of the assessed building have been indicated in Table 5. Sprinklers and fire-rated doors are included in all the evaluations, as these are commonly accepted fire safety features for high-rise buildings. The stair width is maintained at $1 \mathrm{~m}$ as increasing the stair width is not found to result in significant effects on the occupant risk indicator. Note that the above does not imply that a wider stair does not result in a faster evacuation, but that the risk indicator associated with 'smoke entering the staircase' is not influenced significantly by the stair width. In other words, the other fire protection measures are more important than a different stair design, as the smoke should not enter the stairs, and they should therefore be a safe place for the entire evacuation period, even if somewhat varying the duration of this evacuation.

\subsubsection{Influence of stairwell design on occupant safety level}

The effect of different stairwell designs on the RSO is indicated in Figure 3 as a function of the building height (number of stories). Note that the current version of the FRM does not predict a noticeable increase in RSO when increasing the structural fire resistance for these cases, and thus only a single set of curves is visualized which is applicable for fire resistance ratings from 120 to 240 minutes. Equivalency points for which the RSO equals 1 have been indicated. 
As indicated in Figure 3, the FRM does not predict a large increase in occupant safety when introducing a lobby or even a pressurization system. The latter is a result of the high modelled probability that the pressurization will not function properly, see the assumptions and references in Table 2. Only when opting for an air lock system (which is open to the outside) does the FRM indicate a possibility to obtain equivalency for residential high-rise buildings above $100 \mathrm{~m}$.

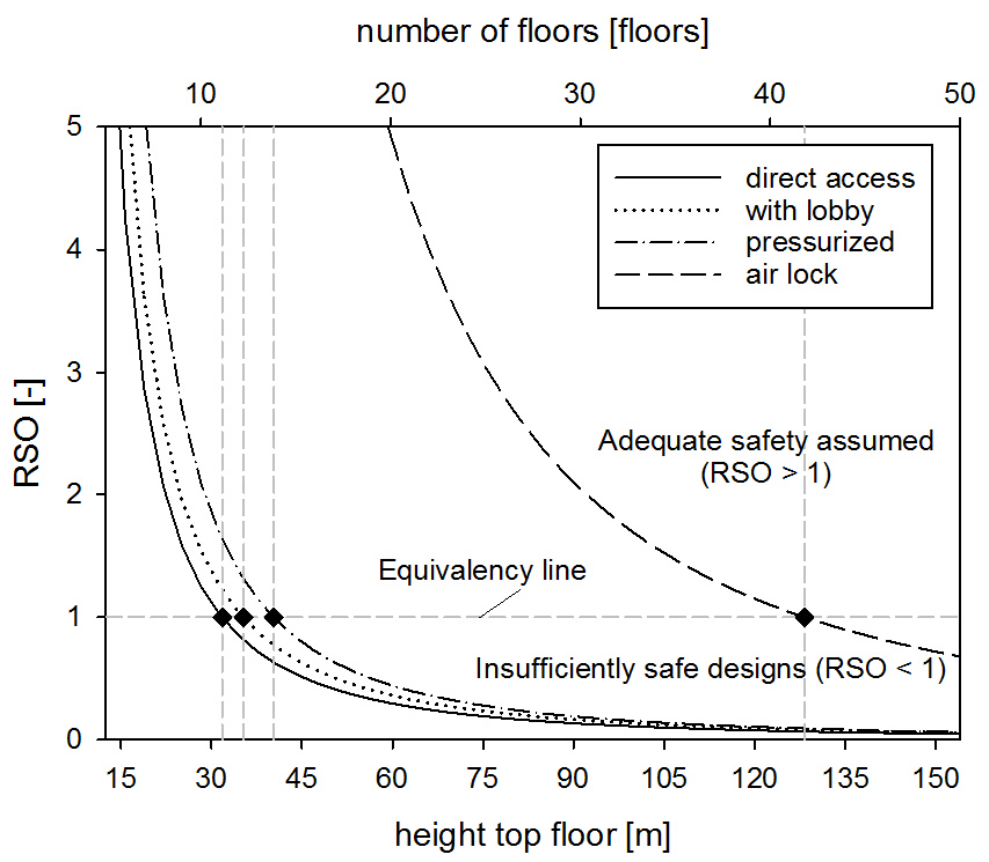

Figure 3: Relative Safety level Occupants (RSO) for different stairwell types. The curves are applicable for structural fire resistance $\mathbf{1 2 0} \mathrm{min}-\mathbf{2 4 0} \mathrm{min}$, no warning system, all other parameters as indicated in Table 5.

\subsubsection{Influence of warning system on occupant safety level}

The FRM assumes that the fire and rescue service opts for a full evacuation, except when it is certain that the fire is small. In case no warning system is available, the fire and rescue service has to manually go door-to-door to warn the occupants and ensure that the evacuation process is initiated, resulting in considerable time-delays for the evacuation process. Including a manual or automatic warning system avoids this and results in a faster evacuation. The manual warning system is activated by the fire and rescue service, while the automatic is activated upon fire detection or sprinkler activation. The automatic system results in a faster warning and an earlier modelled onset of the evacuation, but comes at the cost of nuisance alarms and possibly reduced occupant adherence after a number of false alarms. Nevertheless, the effects on the occupant safety level are compared in Figure 4 for a direct access staircase. Based on these results, providing a warning system can allow to increase the building height without reducing the safety level. The automatic system may however not be feasible for practical reasons, as discussed above. Note that 
the different curves are the same for very low building heights. For these buildings, warning by the fire and rescue service is thus fast that no benefit is obtained from including a dedicated warning system.

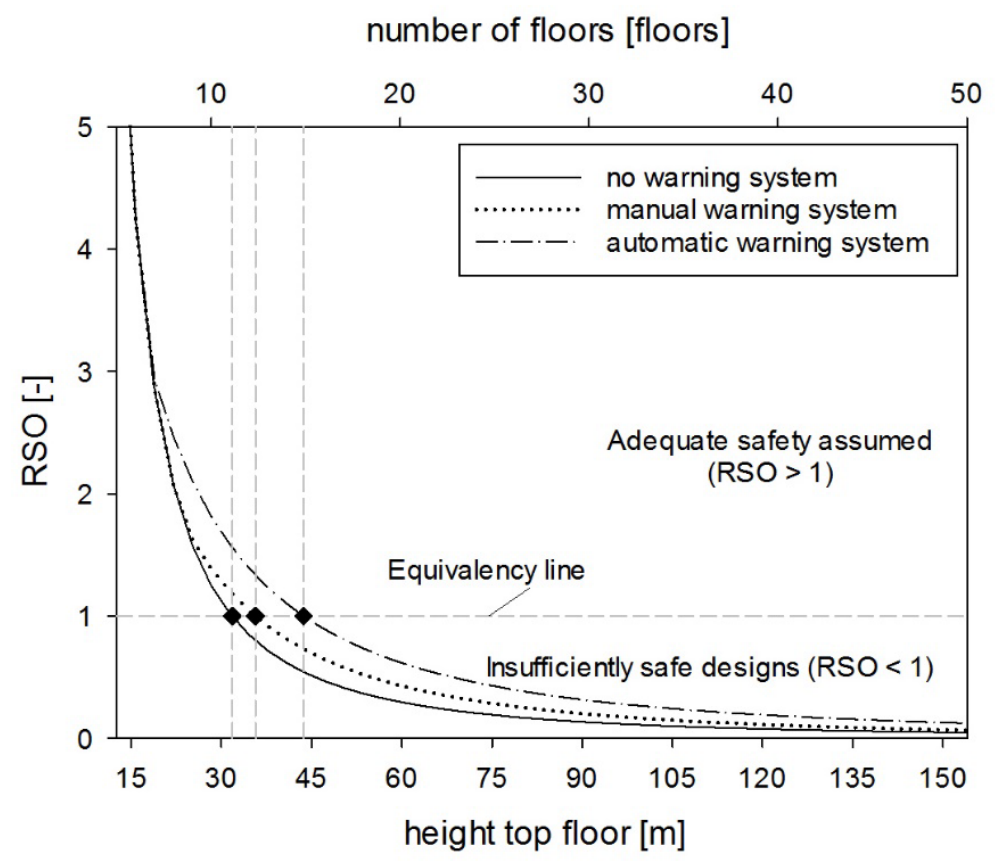

Figure 4: Relative Safety level Occupants (RSO) for different warning systems. The curves are applicable for structural fire resistance $120 \mathrm{~min}-\mathbf{2 4 0} \mathrm{min}$, direct access staircase, all other parameters as indicated in Table 5.

\subsubsection{Influence of fire safety features on property safety level}

Different design options are compared in Figure 5 with respect to the relative property safety level (RSP). The full curve indicates the RSP-values obtained for the reference design when changing height and maintaining all other parameters as in Table 5. For this curve, the RSP equals 1 obtained for a top floor height of $22 \mathrm{~m}$ (i.e. 8 story building) in accordance with the definition of RSP in Eq. (5).

Whereas traditional façade designs considerably limit the probability of fire spreading to other floors due to the spandrel height, modern curtain wall systems do not have a similar safety feature. Consequently, the FRM indicates that from a property loss perspective, sprinklers are required as a compensatory measure for the use of modern façade solutions, even for low building heights. The introduction of sprinklers allows extend the height of the building to approximately $35 \mathrm{~m}$, whereas increasing the fire rating of the structure or introducing other safety features only results in limited further increases in maximum building height. With current modelling of safety features, the FRM indicates an inability to obtain equivalent property protection for buildings above $37 \mathrm{~m}$ when opting for a curtain wall design.

Higher maximum building heights are obtained by combining sprinkler protection with traditional façade design (spandrel height of $1.2 \mathrm{~m}$ ). Note that the sprinkler protection required for property 
protection equivalency also is necessary to obtain equivalency at larger building heights for the occupant safety level (see Figure 3 above). Increasing the structural fire resistance rating does result in an increase of the RSP when considering a traditional façade, as shown in Figure 5.

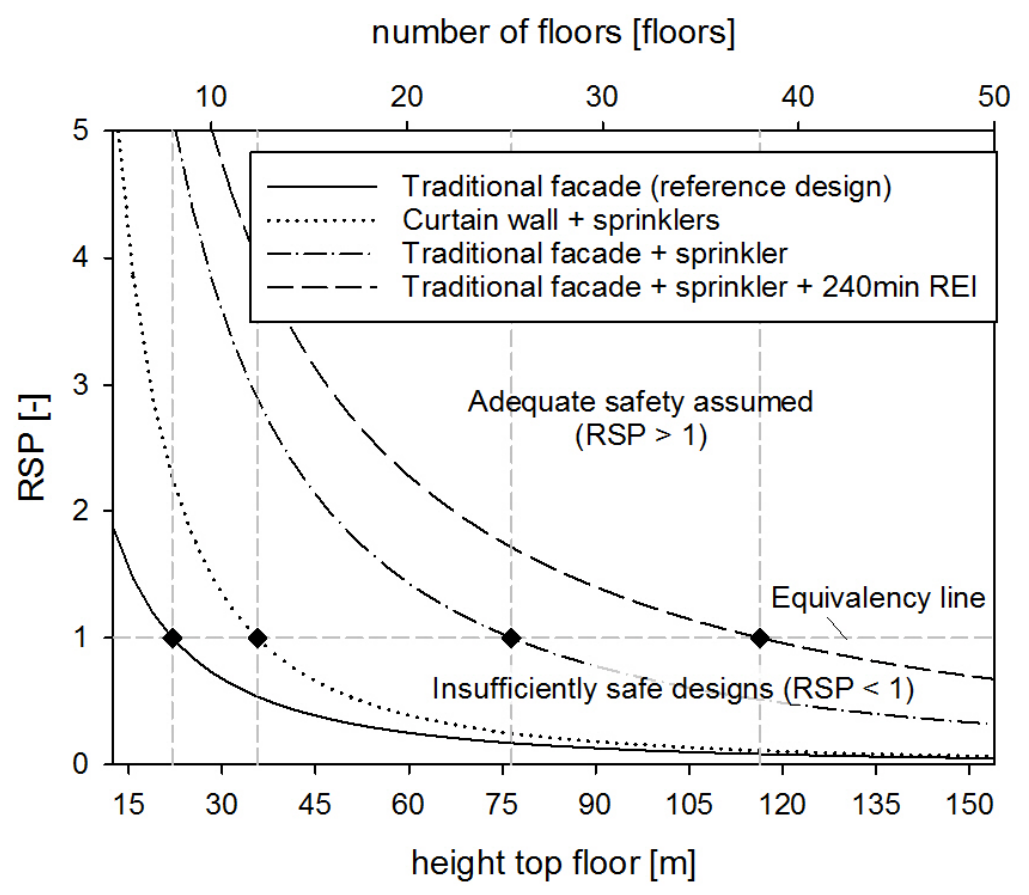

Figure 5: Relative Safety level Property (RSP) for different stairwell types, with curves applicable for structural fire resistance $\mathbf{1 2 0} \mathrm{min}-\mathbf{2 4 0} \mathrm{min}$, all other parameters as indicated in Table 5 


\section{APPLICATION TO SPECIFIC DESIGN CASE}

The curves in Figure 2 - Figure 5 expose some of the height-dependent tradeoffs included in the FRM. For specific applications however, it suffices to evaluate the RSO and RSP for proposed design options. Consider for example the proposal to build a 22 story high residential tower (66 m height of the top floorplate) with 4 apartments per story. Different design options are evaluated in Table 6, where the equality sign indicates that the same parameter value is maintained for all design options. Based on these evaluations, Option 1 is acceptable with respect to the property risk level (25\% improved safety level compared to reference), but its occupant safety performance is inadequate. Option 2 performs excellently with respect to the RSO, but the curtain-wall design results in an unjustifiably low RSP. Design Option 3 performs excellently with respect to the occupant risk and sufficiently well with respect to the property risk level (13\% increased property safety). Based on these FRM evaluations only Option 3 can reasonably be justified for this building height.

Examples with variations including the firefighting elevator and the ASDS are not included, as their contributions towards an improved fire safety level were generally very limited in the model.

Table 6: Description of considered design options and evaluation of RSL, RSP, and design acceptability

\begin{tabular}{|c|c|c|c|}
\hline Parameter & Option 1 & Option 2 & Option 3 \\
\hline Building height [m] & 66 & $=$ & $=$ \\
\hline Number of stories $[-]$ & 22 & $=$ & $=$ \\
\hline Area per story $\left[\mathrm{m}^{2}\right]$ & 600 & $=$ & $=$ \\
\hline Occupants per apartment [persons] & 2.5 & $=$ & $=$ \\
\hline Apartments per story [-] & 4 & $=$ & $=$ \\
\hline Stair type $[-]$ & Direct access & Air lock & Air lock \\
\hline Stair width [m] & 1 & $=$ & $=$ \\
\hline Apartment door & EI30 & EI30 & EI30 \\
\hline Stairwell door & None & EI30 & EI30 \\
\hline Airlock door & None & Non-rated & Non-rated \\
\hline Smoke alarm & Domestic & Domestic & Domestic \\
\hline Sprinkler system & Yes & Yes & Yes \\
\hline $\begin{array}{l}\text { Automatic smoke detection system } \\
\text { (ASDS) }\end{array}$ & None & $=$ & $=$ \\
\hline Fire-fighting elevator & None & $=$ & $=$ \\
\hline Warning system & None & Manual & None \\
\hline Structural fire resistance rating [min] & 120 & 180 & 180 \\
\hline Façade access (for assisted evac) & No & No & No \\
\hline Spandrel height [m] & 1.2 & $\begin{array}{l}\text { Not applicable for } \\
\text { curtain-wall façade }\end{array}$ & 1.0 \\
\hline Façade system & Traditional & Curtain wall & Traditional \\
\hline Glass & Double-pane & $=$ & $=$ \\
\hline Apartment value $C_{0}\left[\mathrm{EUR} / \mathrm{m}^{2}\right]$ & 470 & $=$ & $=$ \\
\hline RSO & 0.25 & 22.0 & 4.01 \\
\hline RSP & 1.25 & 0.35 & 1.13 \\
\hline Adequate safety & No & No & Yes \\
\hline
\end{tabular}




\section{DISCUSSION WITH RESPECT TO THE EQUIVALENT SAFETY PITFALLS}

Some pitfalls associated with demonstrating adequate safety through equivalency were introduced in the introduction (Section 1). These are revisited here to assess the robustness of the FRM recommendations.

1. Prescriptive requirements do not always correspond with societal optimum safety levels.

The FRM uses a $22 \mathrm{~m}$ residential building as a benchmark for both the occupant risk assessment and the property risk assessment. This medium-rise structure is very common and thus the profession and society have extensively experienced the fire safety performance of these structures. Consequently, it can more reasonably be assumed that the safety level implicitly incorporated in prescriptive guidance for this $22 \mathrm{~m}$ residential building corresponds closely with the current societally expected safety level. As the FRM has been developed to be a tool dedicated to the safety assessment of residential buildings, the extrapolation of the expected safety level (and thus the use of the $22 \mathrm{~m}$ building as a safety benchmark) can be considered reasonable for high-rise residential buildings where the fire safety dynamics (evacuation, fire spread...) remain similar. It is considered that the tool should not be applied for very tall residential buildings (for example) more than 150 $\mathrm{m}$ high. Furthermore, it is clear that the FRM cannot be applied to demonstrate adequate safety for other types of high-rise buildings, like offices or hotels.

2. Safety levels in prescriptive guidelines differ between buildings.

The use of the very common reference building in the FRM avoids the introduction of a significant bias. When alternatively using newer prescriptive guidance on high-rise buildings as a reference, the implicit safety level can be considered to be less calibrated by experience and therefore more prone to differences between different prescriptively accepted design solutions. Nevertheless, it is acknowledged that research targeted at comparing different implicit safety levels in the low-rise prescriptive guidance would benefit the reference safety level evaluation in the FRM and the tool's robustness.

3. Application of prescriptive guidelines to structures outside of the guidelines' scope cannot result in a benchmark for adequate safety.

The considered reference building is an explicitly accepted design solution from (Energistyrelsen, 2012a), and the high-rise residential structures considered within the scope of the FRM constitute a very specific extension to the design guidance scope of multi-dwelling residential buildings. The FRM is designed for a specific purpose and should not be applied to justify the design of for example an office building.

4. Modelling assumptions can have asymmetric effects on the reference design and the innovative design solution.

Safety factors can be included to reduce the risk of non-conservative asymmetry effects. An unreasonably high safety factor may however penalize a performance-based design too 
much, resulting in reduced performance (in this case: reduced safety) for the occupants when pushing designers towards prescriptive design. For practical applications, it is suggested to evaluate the relative safety levels RSO and RSP and to discuss the acceptability of the outcome with the stakeholders. This explicitly recognizes that the FRM should be applied as a decision-support tool and cannot be used to blindly decide on safety features. If the FRM indicates the RSO and RSP to be both much larger than unity, this is a strong argument to all stakeholders in favor of accepting the risk level of the proposed design. Furthermore, the FRM has been developed upfront as a decision-support tool for residential high-rise buildings and is thus not project specific. This arguably reduces the risk of (inadvertently) introducing a bias to influence the equivalency evaluation. Nevertheless, it is acknowledged that the asymmetry effect is an important issue for all equivalency evaluations, including the FRM, and needs to be addressed by consultation of experts and the introduction of safety factors when considered appropriate.

\section{CONCLUSIONS}

A risk-based tool, the Fire Risk Model (FRM), has been introduced for evaluating the adequacy of safety features in high-rise single-staircase residential buildings in Denmark. The FRM is based on an evaluation of equivalent risk by comparing the risk level associated with a proposed design solution to the risk level in a low-rise $(22 \mathrm{~m})$ prescriptively accepted design. The concept of defining adequate safety through an equivalency assessment is however not without pitfalls. Possible pitfalls have been discussed and their application to the FRM evaluated. It is concluded that the FRM can be considered to give a robust indication of the acceptability of a design, thanks to the large societal experience with respect to the accepted reference design and the limited extension of scope from the reference design to high-rise residential buildings. Application of the FRM indicates that equivalent safety for high residential buildings (above $45 \mathrm{~m}$ ) can only be obtained by using a stairwell with airlock open to the outside, and when using traditional façade designs (with spandrel). Other stairwell designs (direct access, lobby, pressurization) are found to be too unreliable, resulting in an occupant safety level above the acceptance level defined by the $22 \mathrm{~m}$ high accepted design. Similarly, modern facades with a curtain wall are found to result in an increased property risk due to an increased probability of fire spread to other floors. The above suggests that limiting fire and smoke spread (i.e. compartmentation) is key for both the occupant and property safety levels. By containing the fire to the floor of fire origin, the property risk level can be limited. Similarly, introducing barriers against smoke spreading to the staircase is key for providing safe egress to the occupants. More precise assessments can be made by introducing more detailed statistical data and models into the FRM. Thanks to the FRM's modular design these can easily be implemented. 


\section{REFERENCES}

Acikyol, B.H., Kilic, A., Balik, G. (2017). Experimental Investigation of the Effect of Fire Protection Lobby on Stair Pressurization System in a High-Rise Building. Fire Technology, 53, 135-151.

Axelsson, O., Korostenski, T., Lundin, J., Yndemark, B. (2012). Fire safety design of a super tall building - The Swedish Case Study. Proceedings of the 2012 SFPE Conference on PerformanceBased Codes, 20/06, Hong Kong, People’s Republic of China.

Bellido, C., Quiroz, A., Panizo, A., Torero, J.L. (2009). Performance Assessment of Pressurized Stairs in High Rise Buildings. Fire Technology, 45, 189-200.

Bittern, A., Torero, J.L., Bisby, L. (2011). Tall Building Design - Fit for purpose. The need for realistic design assumptions Proceedings of the $10^{\text {th }}$ International Symposium on Fire Safety Science (IAFSS). 19-24/06, Maryland, USA.

BSI. (2003). PD 7974-7:2003 - Application of fire safety engineering principles in the design of buildings - Probabilistic risk assessment. British Standard.

CEN. (2002). EN 1991-1-2: Eurocode 1: Actions on structures - Part 1-2: General actions Actions on structures exposed to fire. European Standard.

Cowlard, A., Bittern, A., Abecassis-Empis, C., Torero, J. (2013). Fire safety design for tall buildings. Procedia Engineering, 62, 169-181.

Croce, P.A., Grosshandler, W.L., Bukowski, R.W., Gritzo, L.A. (2008). The International FORUM of Fire Research Directors. A position paper on performance-based design for fire code applications. Fire Safety Journal, 43, 234-236.

Ditlevsen, O., Madsen, H.O. (2005). Structural Reliability Methods ( $2^{\text {nd }}$ edition). John Wiley \& Sons, Chichester.

Doron, C.-O. (2016). The experience of 'risk': genealogy and transformations. In. Routledge handbook of Risk Studies. Burgess, A., Alemanno, A., Zinn, J.O. (Eds.). Routledge. New York.

Empis, C.A. (2010). Analysis of the compartment fire parameters influencing the heat flux incident on the structural façade. Doctoral thesis. The University of Edinburgh.

Energistyrelsen. (2010). Bygningsreglementet [Building Regulation] (in Danish).

Energistyrelsen. (2012a). Eksempelsamling om brandsikring af byggeri [Collated Examples of Fire Safety Measures in Buildings] (in Danish).

Energistyrelsen. (2012b). Vejledning om brandsikkerhed i høje bygninger [Guidelines regarding fire safety in tall buildings] (in Danish). 
Erhvervs- og Byggestyrelsen. (1972). Bygningsreglementet [Building Regulation] (in Danish).

Erhvervs- og Byggestyrelsen. (1977). Bygningsreglementet [Building Regulation] (in Danish).

Fischer, K. (2014). Societal decision-making for optimal fire safety. Doctoral thesis, ETH-Zurich.

Flint, G., Usmani, A., Lamont, S., Lane, B., Torero, J. (2007). Structural Response of Tall Buildings to Multiple Floor Fires. J. Struct. Eng., 133, 1719-1732.

Gardiner, J. (2005a). Determination 2005/109. Single means of escape from a high-rise apartment building at 7 Scotia Place, Auckland City. New Zealand Department of Building and Housing.

Gardiner, J. (2005b). Determination 2005/168. Single means of escape from a high-rise apartment building at 47 Wakefield Street, Auckland City. New Zealand Department of Building and Housing.

Hadjisophocleous, G.V., Benichou, N. (1999). Performance criteria used in fire safety design. Automation in Construction, 8, 489-501.

Hall, J.R. (2010). Experience with sprinklers and other automatic fire extinguishment equipment. National Fire Protection Association. Fire Analysis and Research Division. Quincy, MA, USA.

Hansen, N.D. (2012). Development of a fire risk assessment model for tall residential buildings in Denmark. Master dissertation, Technical University of Denmark (DTU).

Hasofer, A.M., Thomas, I. (2006). Analysis of fatalities and injuries in building fire statistics. Fire Safety Journal, 41, 2-14.

Hasofer, A., Beck, V., Bennetts, I. (2007). Risk Analysis in Building Fire Safety Engineering. Elsevier.

He, Y., Grubits, S. (2010). A Risk-based Equivalence Approach to Fire Resistance Design for Buildings. Journal of Fire Protection Engineering, 20, 5-26.

Hopkin, D., Van Coile, R., Lange, D. (2017). Certain Uncertainty - Demonstrating safety in fire engineering and the need for safety targets. SFPE Europe, 07.

Ikeda, K., Sekizawa, A. (2005). Collapse mechanism of the Windsor building by fire in Madrid and the plan for its demolition process. Proceedings of the International Workshop on Emergency Response and Rescue. Taipei, Taiwan.

Johansson, U.C. (2010). Quantifying risk for deemed-to-satisfy apartment buildings. Master dissertation, Lund University.

Kahneman, D. (2011). Thinking Fast and Slow. Farrar, Straus and Giroux, New York. 
Klote, J.H. (2004). Tenability and open doors in pressurized stairwells. ASHRAE transactions, vol. 10, part 1.

Kobenhavns Kommune. (2006). Hojhuse I kobenhavn. Strategi for byens profil - oplaeg til debat. (in Danish).

Lange, D., Roben, C., Usmani, A. (2012). Tall building collapse mechanisms initiated by fire: Mechanisms and design methodology. Engineering Structures, 36, 90-103.

Lundin, J. (2005). Safety in case of fire - The effect of changing regulations. Doctoral thesis, Lund University.

Meacham, B.J. (2004). Understanding risk: Quantification, perceptions, and characterization. Journal of Fire Protection Engineering, 14, 199-227.

Nathwani, J., Lind, N.C., Pandey, M.D. (1997). Affordable Safety By Choice: The Life Quality Method. University of Waterloo.

Proulx, G. (2008). Movement of people: Evacuation timing. SFPE Handbook of Fire Protection Engineering, 3.342-3.366.

Sikkerhedsstyrelsen. (2001). Staerkstromsbekendgorelsen. (in Danish).

Spinardi, G., Bisby, L., Torero, J. (2017). A review of sociological issues in fire safety regulation. Fire Technology, 53, 1011-1037.

Van Coile, R., Allardice, N., Dagneryd, A., Hourqueig, R. (2015). Reliability-based tool for the assessment of External Fire Spread between buildings. Proceedings of the $11^{\text {th }}$ conference on Performance-Based Codes and Fire Safety Design Methods, 22-27/05, Warsaw, Poland.

Vrijling, J. van Hengel, W., Houben, R. (1995). A framework for risk evaluation. Journal of Hazardous Materials, 43, 245-261.

Wu, Z., Li, H., He, Y., Zhou, D. and Wang, J., (2014). Comparative Evaluation Method for Fire Safety Design of Large Storage Spaces. Fire Safety Science, 11, 933-943. 